\title{
MODIFICATION OF AMINO ACID RESIDUES IN THE S; BINDING SITE OF CARBOXYPEPTIDASE Y
}

\author{
by \\ KLAUS BREDDAM \\ Department of Chemistry, Carlsberg Laboratory, \\ Gamle Carlsberg Vej 10, DK-2500 Copenhagen Valby
}

\begin{abstract}
Keywords: Carboxypeptidase $Y$, chemical modification, hydrogen peroxide, kinetics, fluorodinitrobenzene
\end{abstract}

Carboxypeptidase $\mathrm{Y}$ was treated under different conditions with various reagents in order to chemically modify amino acid side-chains located in the $S_{1}^{\prime}$ binding site. Treatment of carboxypeptidase $Y$ with $\mathrm{H}_{2} \mathrm{O}_{2}$ in phosphate buffer caused a reduction in the peptidase activity towards FA-Phe-Leu-OH to $25 \%$ of the control while the esterase activity towards FA-Phe-OMe, the amidase activity towards FA-Phe- $\mathrm{NH}_{2}$ and the peptidyl amino acid amide hydrolase activity towards FA-Phe-Gly- $\mathrm{NH}_{2}$ were much less affected. The loss of peptidase activity could be correlated with the oxidation of a single methionyl residue, thus forming a methionyl sulfoxide derivative. When the reaction was performed in acetate buffer under otherwise identical conditions an additional methionyl residue was oxidized with the result that all activities of the enzyme increased while the heat stability of the enzyme decreased drastically.

${ }^{14} \mathrm{C}$-Fluorodinitrobenzene influenced the activities of carboxypeptidase $\mathrm{Y}$ in a manner similar to that observed with $\mathrm{H}_{2} \mathrm{O}_{2}$ in phosphate buffer. The loss of peptidase activity could be correlated with the incorporation of a single equivalent of reagent as an O-DNP-tyrosyl derivative.

The carboxypeptidase $\mathrm{Y}$ derivatives containing a single methionyl sulfoxide residue or an O-DNP-tyrosyl residue both exhibited altered specificity with respect to the $P$ ' position of the substrate. These results indicate that both the methionyl residue and the tyrosyl residue are located in the $S_{i}^{\prime}$ binding site.

\section{INTRODUCTION}

In a recent paper from this laboratory it was demonstrated that the $S_{i}$ binding site of CPD-Y contains a methionyl residue which could be modified with alkylating reagents, e.g. iodoace- tamide or phenacylbromide (7), thus in both cases introducing a sulfonium ion and a rather bulky group. These derivatives of CPD-Y exhibit specificities with respect to the $P_{1}^{\prime}$ position of all types of substrates which drastically deviate

Abbreviations: $\mathrm{Bz}=$ benzoyl; Bzl = benzyl; CPD-Y = carboxypeptidase $\mathrm{Y} ; \mathrm{DNP}=$ dinitrophenyl; EDTA = ethylenediamine tetraacetic acid, sodium salt; $\mathrm{FA}=$ furylacryloyl; Hepes $=\mathrm{N}$-2-hydroxyethylpiperazine-N-2ethane sulfonic acid; IAA-CPD-Y = CPD-Y modified with iodoacetamide; Mes = 2-(N-morpholino)ethane sulfonic acid; Met-SO = methionine sulfoxide; Met-SO-CPD-Y = CPD-Y containing one methionyl sulfoxide residue; (Met-SO) ${ }_{2}$-CPD-Y $=$ CPD-Y containing two methionyl sulfoxide residues; $m-N P A B-C P D-Y=C P D-Y$ modified with meta-nitrophenacylbromide; PAB-CPD-Y = CPD-Y modified with phenacylbromide; $p-H M B=$ para-hydroxymercuribenzoate; $p-N P A B-C P D-Y=C P D-Y$ modified with para-nitrophenacylbromide. The binding site notation is that of SCHECHTER and BERGER (17). Accordingly, the binding site for the C-terminal amino acid residue of the substrate is denoted $S_{;}^{\prime}$ and those for the amino acid residues in the amino terminal direction away from the scissile bond is denoted $S_{1}, S_{2}, \ldots ., S_{n}$. 
from that of unmodified CPD-Y (7). Other amino acid side-chains might be located in the $S_{t}^{\prime}$ binding site and hence, it was of interest to establish whether the introduction of other groups in this portion of the enzyme would cause similar drastic changes in its specificity. The present paper describes the oxidation of the methionyl in the $S_{1}^{\prime}$ binding site and in addition, the modification of a tyrosyl residue situated in the same area. It is demonstrated that the specificities of these modified enzymes deviate less from that of unmodified CPD-Y than observed for the derivatives containing the methionine sulfonium groups (7). It is further shown that the modification of another methionyl residue located in a different portion of the enzyme molecule also changes the catalytic properties of the enzyme.

\section{MATERIALS AND METHODS}

\subsection{Materials}

The following compounds were synthesized as previously described: FA-L-Phe- $\mathrm{NH}_{2}$ (4), FAL-Phe-L-Gly-NH $\mathrm{NH}_{2}$ (4), FA-L-Phe-L-Gly-OH (4), FA-L-Phe-L-Ala-OH (7), FA-L-Phe-L-Leu-OH (7), FA-L-Ala-OBzl (7), FA-L-Ala-OEt (7), FAL-Phe-L-Val- $\mathrm{NH}_{2}$ (7), CABS-Sepharose (4). Biogel P-4 was obtained from Biorad, USA, CPD-Y from Carlsberg Biotechnology Ltd., Tagensvej 16, DK-2200 Copenhagen N; FA-L-Phe-OMe and Z-D-Ala-L-Phe-OH from Bachem, Switzerland; (D,L)-benzylsuccinic acid from Burdick and Jackson, USA; N-bromosuccinimide, acrylonitrile and phenacylbromide from Fluka, Switzerland; Mes, Hepes, $\beta$-propiolactone, iodoacetic acid and FDNB from Sigma, USA; trinitrobenzene sulfonic acid from Pierce, USA; $\mathrm{ICl}$ and tetranitromethane from EGA Chemie, W. Germany; ${ }^{14} \mathrm{C}$-FDNB from Amersham, England. All other chemicals and solvents were of analytical purity and obtained from Merck, W. Germany.

\subsection{Methods}

\subsubsection{Modifications of CPD-Y}

The influence of various reagents on the esterase, amidase, peptidyl amino acid amide hydrolase and peptidase activities of CPD-Y was studied using FA-Phe $\_$OMe, FA-Phe $-\mathrm{NH}_{2}$, FAPhe $-\mathrm{Gly}-\mathrm{NH}_{2}$ and FA-Phe-Leu-OH as substrates, respectively. The assay with FA-Phe Leu-OH was performed in $0.05 \mathrm{M}$-Mes, $1 \mathrm{mM}$ EDTA, pH 6.5, and with the other substrates $0.05 \mathrm{M}$-Hepes, 1 mM-EDTA, pH 7.5 was used. The assay mixture consisted of $965 \mu \mathrm{l}$ buffer, 25 Hl $12 \mathrm{mM}$ substrate dissolved in methanol and 10 $\mu \mathrm{l}$ aliquots of the reaction mixture, added directly or after an appropriate dilution in water. The rate of hydrolysis was followed spectrophotometrically at $337 \mathrm{~nm}$ using a Cary 219 spectrophotometer, thermostated at $25^{\circ} \mathrm{C}$. All modification reactions of CPD-Y were carried out at room temperature using an enzyme concentration of $5.3 \mathrm{mg} / \mathrm{ml}$. Control reactions without reagent added ensured that the enzyme was stable under the employed conditions. Reactions were terminated by separating the enzyme from reagent by gel filtration on Biogel P-4, equilibrated with water. The bed volume was 20-30 times the volume of the sample applied. The modified preparations of CPD-Y were stored frozen in water at $-18^{\circ} \mathrm{C}$. Modification of CPD-Y in the presence of inhibitor was performed by addition of $50 \mu 11 \mathrm{M}$-Z-D-Ala-L-Phe$\mathrm{OH}$ or $12.5 \mu \mathrm{l} 0.4 \mathrm{M}-(\mathrm{D}, \mathrm{L})$-benzylsuccinic acid dissolved in ethanol per $\mathrm{ml}$ reaction medium, followed by readjustment of $\mathrm{pH}$.

\subsubsection{Characterization of modified CPD-Y}

The preparations of modified enzyme obtained after gel filtration were analyzed for amino acid composition and for the incorporation of radioactively labelled reagent (only for FDNB). The amino acid composition was determined after acid hydrolysis for 24 hours in vacuo using a Durrum D 500 amino acid analyzer. The content of Tyr was determined employing a special program capable of separating it from glucosamine, another component of CPD-Y. Methionine sulfoxide was determined indirectly since it reverts almost completely to methionine during acid hydrolysis (15). The following procedure converts all methionine in unmodified CPD-Y to homoserine and homoserine lactone: $1 \mathrm{mg}$ lyophilized enzyme was dissolved in $140 \mu \mathrm{l}$ $70 \%$ formic acid and the solution was purged with nitrogen for $10 \mathrm{~min}$. Cyanogen bromide ( 10 $\mathrm{mg}$ ) was added and the solution again purged 
with nitrogen for $1 \mathrm{~min}$. The reaction vessel was sealed and stored in the dark for 22 hours. Nitrogen was then bubbled through the solution for 3 hours, the sample evaporated to dryness, subjected to acid hydrolysis and amino acid analysis. Since methionine sulfoxide is resistant to cyanogen bromide treatment (15) its content could be quantitated as methionine in the acid hydrolysates of cyanogen bromide treated enzyme preparations.

Spectra were recorded using a Cary 219 spectrophotometer, the content of free cysteine was estimated by titration with para-hydroxymercuribenzoate as described by RIORDAN and VALLEE (14) and the carbohydrate content was estimated by the phenol-sulfuric acid method of DuBois (8). ${ }^{14} \mathrm{C}$-measurements were performed by liquid scintillation using a Beckman scintillation counter, Model LS 3155 T. The stoichiometry of the incorporated reagent was based on spectrophotometrically determined enzyme concentrations using $A_{280}=14.8(10)$.

Modification of Met-SO-CPD-Y with phenacylbromide was performed at an enzyme concentration of $5.0 \mathrm{mg} / \mathrm{ml}$ in $0.03 \mathrm{M}-\mathrm{NaH}_{2} \mathrm{PO}_{4}$, $0.12 \mathrm{M}-\mathrm{NaCl}, 2.5 \%$ methanol, $6.2 \mathrm{mM}$-phenacylbromide, $\mathrm{pH} 6.5$ as previously described (7).

\subsubsection{Determination of kinetic constants}

Modified CPD-Y was separated from unmodified enzyme by affinity chromatography as previously described (7) before it was characterized kinetically. The kinetic constants for the hydrolysis of various FA-peptide and ester substrates were determined from Lineveawer-Burk plots. Such determinations were not possible with peptide amides due to their low solubility combined with high $K_{m}$ values. With these substrates only $\mathrm{k}_{\mathrm{cas}} / \mathrm{K}_{\mathrm{m}}$ was determined by following the hydrolysis to completion at a single concentration of substrate and using the integrated form of the Michaelis-Menten equation as described in ref. 18. With FA-Phe-Gly- $\mathrm{NH}_{2}$ and $\mathrm{FA}-\mathrm{Phe}-\mathrm{Val}-\mathrm{NH}_{2}$ direct amino acid analysis of the assay mixture ascertained that the enzyme only released $\mathrm{H}-\mathrm{Gly}-\mathrm{NH}_{2}$ and $\mathrm{H}-\mathrm{Val}-\mathrm{NH}_{2}$, respectively, and not $\mathrm{NH}_{3}$ followed by the C-terminal amino acid. Hydrolysis rates were determined spectrophotometrically at $329-358 \mathrm{~nm}$ and $25{ }^{\circ} \mathrm{C}$. Peptide substrates were assayed in $0.05 \mathrm{M}$-Mes, $1 \mathrm{~mm}$-EDTA, pH 6.5 whereas ester and amide substrates were assayed in $0.05 \mathrm{M}$ Hepes, 1 mM-EDTA, pH 7.5.

\subsubsection{Stabilty of CPD-Y derivatives}

The stability of CPD-Y derivatives was investigated by incubating the enzymes at different temperatures in $0.05 \mathrm{M}$-Mes, $1 \mathrm{mM}$-EDTA, $\mathrm{pH} 6.0$ at a concentration of $0.1-0.2 \mathrm{mg} / \mathrm{ml}$. The inactivation was followed by assay of the activity towards FA-Phe-Leu-OH. The influence of the temperature on the rate constant $k$ was determined and the activation energy $E_{a}$ was determined from the Arrhenius equation, $k=A \cdot e^{-\left(E_{d} / R T\right)}$, by plotting $\log k$ as a function of $T^{-1}$.

\section{RESULTS}

\subsection{Selection of reagents}

Since CPD-Y exhibits a preference for hydrophobic groups in the $P_{i}^{\prime}$ position of all types of substrates (9) it is probable that the $S_{1}$ binding site contains mostly hydrophobic amino acid residues. Among these Tyr, Trp, Cys and Met contain functional groups which may be modified, and CPD-Y was consequently treated with a series of reagents known to attack these amino acid side-chains (Table I). During the reactions the activities of the enzyme towards FA-Phe $\downarrow$ Leu-OH and FA-Phe - OMe were assayed since previous studies (7) had shown that the introduction of labels in the $S_{i}$ binding site of the enzyme would reduce the activity of the enzyme towards FA-Phe-Leu-OH which contains the bulky -Leu-OH group at the P' position to a larger extent than the activity towards FA-Phe-OMe which contains the small -OMe group in this position. It is observed that some of the reagents abolished both activities completely while others had no influence on either activity and both these types of reagents are without interest for the present study (Table I). However, in the reactions with FDNB and $\mathrm{H}_{2} \mathrm{O}_{2}$ the activity towards FA-Phe-Leu-OH was reduced much more than the activity towards FA-Phe! OMe (Table I) and hence, these two reactions were studied in further detail. 
Table I.

Chemical modifications of carboxypeptidase $\mathbf{Y}$

\begin{tabular}{lccc}
\hline & \multicolumn{3}{c}{ \% Residual activity } \\
\cline { 2 - 4 } Reagent & FA-Phe-Leu-OH & FA-Phe-OMe \\
\hline Trinitrobenzene- & & & \\
sulfonic acid & 100 & 100 & $\mathrm{a})$ \\
Fluorodinitrobenzene & 5 & 100 & $\mathrm{~b})$ \\
Ethyleneimine & 100 & 100 & $\mathrm{c})$ \\
Acrylonitrile & 100 & 100 & $\mathrm{~d})$ \\
Methyliodide & 45 & 45 & e) \\
$\beta$-propiolactone & 2 & 5 & $\mathrm{f})$ \\
Iodoacetate & 100 & 100 & $\mathrm{~g})$ \\
ICl & 0 & 0 & $\mathrm{~h})$ \\
Iodine & 0 & 0 & $\mathrm{i})$ \\
Tetranitromethane & 25 & 40 & j) \\
$\mathrm{H}_{2} \mathrm{O}_{2}$ & 27 & 88 & k) \\
N-bromosuccinimide & 15 & 30 & l) \\
\hline
\end{tabular}

The reactions were performed at an enzyme concentration of $4-6 \mathrm{mg} / \mathrm{ml}$ under the following conditions: a) $0.1 \mathrm{M}-\mathrm{NaH}_{2} \mathrm{PO}_{4}, 11 \mathrm{mM}$ reagent, $\mathrm{pH} 8.0$, reaction time: $210 \mathrm{~min}$, b) $0.1 \mathrm{M}-\mathrm{NaH}_{2} \mathrm{PO}_{4}, 14 \mathrm{mM}$ reagent, pH 8.0, reaction time: $300 \mathrm{~min} ., \mathrm{c}) 0.05 \mathrm{M}-\mathrm{NaHCO}_{3}$, $20 \mathrm{mM}$ reagent, $\mathrm{pH} 8.6$, reaction time: $300 \mathrm{~min} ., \mathrm{d}$ ) $0.1 \mathrm{M}-\mathrm{NaH}_{2} \mathrm{PO}_{4}, 38 \mathrm{~mm}$ reagent, $\mathrm{pH} 8.0$, reaction time: $90 \mathrm{~min}$, e) $0.1 \mathrm{M}-\mathrm{NaHCO}_{3}, 100 \mathrm{~mm}$ reagent, pH 9.0, reaction time: $300 \mathrm{~min} ., \mathrm{f}$ ) in water ( $\mathrm{pH}$ stat), 600 mM reagent, pH 4.5, reaction time: $75 \mathrm{~min}, \mathrm{~g}$ ) 0.05 $\mathrm{M}-\mathrm{NaH}_{2} \mathrm{PO}_{4}, 0.2 \mathrm{M}$ reagent, $\mathrm{pH} 6.5$, reaction time: $300 \mathrm{~min}$, h) $0.05 \mathrm{M}-\mathrm{NaH}_{2} \mathrm{PO}_{4}, 0.2 \mathrm{M}-\mathrm{NaCl}, 1.6 \mathrm{~mm}$ reagent, $\mathrm{pH} 6.5$, reaction time: $3 \mathrm{~min}$. , i) $0.1 \mathrm{M}$ $\left.\mathrm{NaHPO}_{4}, 0.1 \mathrm{M}-\mathrm{KI},\right\rfloor \mathrm{mM}$ reagent, $\mathrm{pH} 8.0$, reaction time: $5 \mathrm{~min}$., j) $0.1 \mathrm{M}$-Tris, $3.4 \mathrm{mM}$ reagent, $\mathrm{pH} 8.0$, reaction time: $330 \mathrm{~min} .$, k) $0.1 \mathrm{M}-\mathrm{NaHPO}_{4}, 0.19 \mathrm{M}$ reagent, $\mathrm{pH} 4.75$, reaction time: $140 \mathrm{~min} .$, l) 0.05 $\mathrm{M}$-sodium acetate, $2.5 \mathrm{mM}$ reagent, $\mathrm{pH} 5.0$, reaction time: $40 \mathrm{~min}$.

\subsection{Modification of CPD-Y with $\mathrm{H}_{2} \mathrm{O}_{2}$}

The influence of $\mathrm{H}_{2} \mathrm{O}_{2}$ on the activities of CPD-Y was studied using two different reaction media, i.e. sodium phosphate and sodium acetate buffers. Initially, the reaction was carried out in $0.1 \mathrm{M}-\mathrm{NaH}_{2} \mathrm{PO}_{4}, \mathrm{pH} 4.75$ using 0.19 $\mathrm{M}-\mathrm{H}_{2} \mathrm{O}_{2}$ (Figure 1) and within $2 \frac{1}{2}$ hours the peptidase activity of CPD-Y towards FA-Phe $\downarrow$ Leu-OH had decreased to approximately $25 \%$ of the control (Figure 1A). Smaller reductions were observed in the esterase activity towards FAPhe $\mathrm{OMMe}$, the amidase activity towards FA$\mathrm{Phe}=\mathrm{NH}_{2}$ and the peptidyl amino acid amide

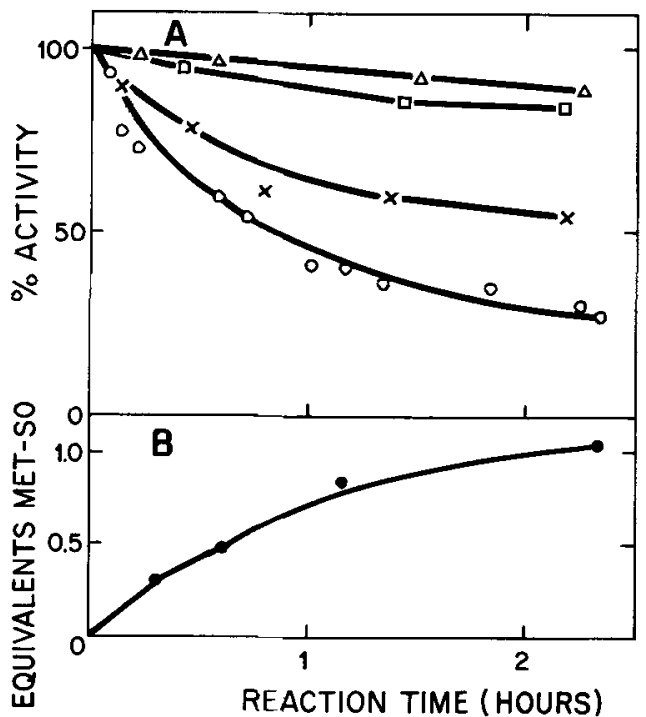

Figure 1. Modification of CPD-Y with $\mathrm{H}_{2} \mathrm{O}_{2}$. Reaction

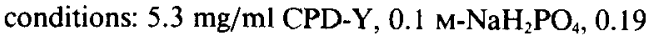
$\mathrm{M}-\mathrm{H}_{2} \mathrm{O}_{2}, \mathrm{pH}$ 4.75. The activities of the enzyme towards FA-Phe-Leu-OH (-O-O-), FA-Phe- $\mathrm{NH}_{2}$ (- $\left.\square-\square-\right)$, FA-Phe-OMe $(-\Delta-\Delta-)$ and FA-Phe $\downarrow$ Gly-NH $\mathrm{NH}_{2}(-x-x-)$ were assayed during the reaction (Panel A). At different times aliquots of the reaction mixture were desalted and the amino acid composition determined. The content of Met-SO was expressed as residues per mole enzyme (Panel B).

hydrolase activity towards FA-Phe $\_$Gly- $\mathrm{NH}_{2}$. The carbohydrate content and amino acid composition of the modified enzyme, as determined after acid hydrolysis, was identical to that of unmodified CPD-Y, and the UV-spectrum and

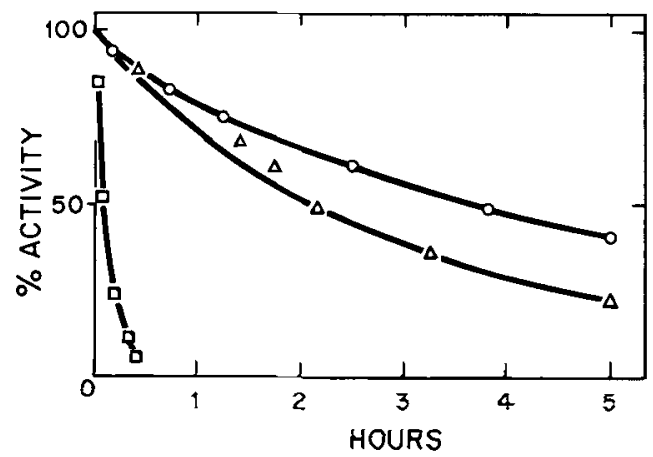

Figure 2. Inactivation of CPD-Y (-O-O-), Met-SOCPD-Y $(-\Delta-\Delta-)$, (Met-SO) $)_{2}$ CPD-Y $(-\square-\square-)$ at $50^{\circ} \mathrm{C}$ in $0.05 \mathrm{M}$-Mes, $1 \mathrm{~mm}$-EDTA, pH 6.5 . 
Table II.

Kinetic parameters for the hydrolysis of ester, peptide and amide substrates by CPD-Y, DNP-CPD-Y and Met-SO-CPD-Y.

\begin{tabular}{|c|c|c|c|c|c|}
\hline Substrate & Enzyme & $\begin{array}{l}\text { Substrate range } \\
(\mathrm{mM})\end{array}$ & $\begin{array}{l}k_{\mathrm{cat}} \\
\left(\min ^{-1}\right)\end{array}$ & $\begin{array}{l}\mathrm{K}_{\mathrm{m}} \\
(\mathrm{mM})\end{array}$ & $\begin{array}{l}\mathrm{k}_{\mathrm{cat}} / \mathrm{K}_{\mathrm{m}} \\
\left(\mathrm{min}^{-1} \cdot \mathrm{mM}^{-1}\right)\end{array}$ \\
\hline \multirow{3}{*}{ FA-Phe-OMe } & CPD-Y & & 11000 & 0.39 & 28000 \\
\hline & Met-SO-CPD-Y & $0.1-1.0$ & 14200 & 1.0 & 14200 \\
\hline & DNP-CPD-Y & $0.06-0.4$ & 5800 & 0.21 & 28000 \\
\hline \multirow{3}{*}{ FA-Phe $=O E t$} & CPD-Y & & 11000 & 0.059 & 190000 \\
\hline & Met-SO-CPD-Y & $0.03-3.0$ & 14200 & 0.14 & 101000 \\
\hline & DNP-CPD-Y & $0.07-0.4$ & 3200 & 0.19 & 17000 \\
\hline \multirow{3}{*}{ FA-Ala-OEt } & CPD-Y & & 4600 & 1.0 & 4600 \\
\hline & Met-SO-CPD-Y & $0.05-5.0$ & 11900 & 2.9 & 4100 \\
\hline & DNP-CPD-Y & $0.6-5.0$ & 3000 & 2.9 & 1030 \\
\hline \multirow{3}{*}{ FA-Ala-OBzl } & CPD-Y & & 9100 & 0.054 & 170000 \\
\hline & Met-SO-CPD-Y & $0.05-0.5$ & 10900 & 0.67 & 16300 \\
\hline & DNP-CPD-Y & $0.05-0.5$ & 4400 & 0.26 & 17000 \\
\hline \multirow{3}{*}{ FA-Phe-Gly-OH } & CPD-Y & & 5800 & 5.4 & 1100 \\
\hline & Met-SO-CPD-Y & $0.7-5.0$ & -2300 & -30 & 80 \\
\hline & DNP-CPD-Y & $0.7-5.0$ & $\sim 1300$ & $\sim 12$ & 110 \\
\hline \multirow{3}{*}{ FA-Phe-Ala-OH } & CPD-Y & & 9700 & 0.14 & 61000 \\
\hline & Met-SO-CPD-Y & $0.15-1.5$ & 4900 & 2.2 & 2200 \\
\hline & DNP-CPD-Y & $0.15-1.5$ & 1100 & 1.5 & 730 \\
\hline \multirow{3}{*}{ FA-Phe-Leu-OH } & CPD-Y & & 4900 & 0.021 & 230000 \\
\hline & Met-SO-CPD-Y & $0.05-0.5$ & 1600 & 0.16 & 10000 \\
\hline & DNP-CPD-Y & $0.05-0.5$ & 600 & 0.26 & 2300 \\
\hline \multirow{3}{*}{ FA-Phe- $-\mathrm{NH}_{2}$} & CPD-Y & & & & 89 \\
\hline & Met-SO-CPD-Y & 0.5 & & & 72 \\
\hline & DNP-CPD-Y & 0.5 & & & 42 \\
\hline \multirow{3}{*}{ FA-Phe-Gly-NH } & CPD-Y & & & & 160 \\
\hline & Met-SO-CPD-Y & 0.5 & & & 72 \\
\hline & DNP-CPD-Y & 0.5 & & & 26 \\
\hline \multirow{3}{*}{ FA-Phe-Val-NH } & CPD-Y & & & & 6200 \\
\hline & Met-SO-CPD-Y & 0.1 & & & 640 \\
\hline & DNP-CPD-Y & 0.1 & & & 41 \\
\hline
\end{tabular}

The rates of hydrolysis were determined spectrophotometrically at $329-358 \mathrm{~nm}$. For ester and amide substrates assays were performed in $0.05 \mathrm{M}$-Hepes, $1 \mathrm{~mm}$-EDTA, $2.5 \%$ methanol, $\mathrm{pH} 7.5$ and for peptide substrates 0.05 M-Mes, 1 mm-EDTA, pH 6.5 was used. In the case of FA-Phe-Val- $\mathrm{NH}_{2}$ methanol was replaced with dimethylformamide. The data for CPD-Y were from reference 7.

p-HMB titration indicated that neither the tryptophan content nor the free sulfhydryl group was affected. However, the Met-SO content increased from 0 to 1.0 equivalent during the reaction (Figure $1 \mathrm{~B}$ ).

The modified enzyme (Met-SO-CPD-Y) was separated from unmodified enzyme by affinity chromatography (see section 2.2.3) and after $2 \mathrm{~h}$ $20 \mathrm{~min}$ the reaction mixture contained only $4-5 \%$ unmodified enzyme. Thus, the activity changes observed in Figure 1A correlates with the modification of a single methionyl residue in 
CPD-Y. When the reaction was performed in the presence of the inhibitor benzylsuccinic acid the activities of CPD-Y were essentially unaffected by $\mathrm{H}_{2} \mathrm{O}_{2}$ within three hours suggesting that the methionyl residue modified in the absence of this inhibitor is located in the active site of CPD-Y.

Met-SO-CPD-Y was found to inactivate at 50 ${ }^{\circ} \mathrm{C}$ in an apparent first order reaction with a rate constant $\mathrm{k}$ of $4.9 \cdot 10^{-3} \mathrm{~min}^{-1}$ as compared with $3.3 \cdot 10^{-3} \mathrm{~min}^{-1}$ for the unmodified enzyme (Figure 2). The influence of the temperature on $k$ indicated that this reaction had an activation energy $E_{a}$ of $320 \mathrm{~kJ} \cdot$ mol $^{-1}$ for the unmodified enzyme and $310 \mathrm{~kJ} \cdot \mathrm{mol}^{-1}$ for Met-SO-CPD-Y. Thus, the introduction of an oxygen atom on a methionyl residue in CPD-Y forming Met-SOCPD-Y seems to have only a slight adverse effect on the stability of the enzyme.

Met-SO-CPD-Y was kinetically characterized using a series of FA-substrates which were selected such that they primarily reflected the influence of the modification on the leaving group specificity of CPD-Y. The hydrolysis of all the ester substrates listed in Table II was characterized by increased $\mathrm{k}_{\text {cat }}$ and $\mathrm{K}_{\mathrm{m}}$ values relative to unmodified CPD-Y. $k_{\text {cal }} / K_{m}$ decreased for all the ester substrates but interestingly it decreased to approximately $10 \%$ for $\mathrm{FA}-\mathrm{Ala}\rfloor \mathrm{OBzl}$ containing a bulky leaving group while only to $50-90 \%$ for FA-Phe-OMe, FA-Phe-OEt and FA-Ala $\_$OEt containing non-bulky leaving groups. The hydrolysis of the peptide substrates FA-Phe=Gly. $\mathrm{OH}, \mathrm{FA}-\mathrm{Phe}-\mathrm{Ala}-\mathrm{OH}$ and FA-Phe-Leu-OH by Met-SO-CPD-Y was also characterized by reduced $k_{\mathrm{ca} a} / K_{\mathrm{m}}$ values but in contrast to the ester substrates this was both due to a reduction in $\mathrm{k}_{\text {cat }}$ and an increase in $\mathrm{K}_{\mathrm{m}}$. However, with peptide substrates the size of the leaving group influenced the reduction in $\mathrm{k}_{\text {cat }} / \mathrm{K}_{\mathrm{m}}$ less than observed with the ester substrates. The hydrolysis of FA-Phe $-\mathrm{NH}_{2}$, FA-Phe ${ }^{\downarrow} \mathrm{Gly}-\mathrm{NH}_{2}$ and FA-Phe Val- $\mathrm{NH}_{2}$ by Met-SO-CPD-Y were characterized by $\mathrm{k}_{\mathrm{ca}} / \mathrm{K}_{\mathrm{m}}$ values which were $80 \%, 20 \%$ and $5 \%$ of those obtained with unmodified CPD-Y, respectively, and, as observed with ester substrates, this suggests that the sulfoxide group in Met-SO-CPD-Y adversely influences the interaction between enzyme and substrates with bulky leaving groups.
The results obtained with Met-SO-CPD-Y are consistent with the modified methionyl residue being located in the $S_{\text {, binding site. This location }}^{\prime}$ was also assigned to the methionyl residue which reacts with alkylating reagents, e.g. iodoacetamide and phenacylbromide, and to establish whether the site of reaction of $\mathrm{H}_{2} \mathrm{O}_{2}$ and the alkylating reagents is identical, Met-SO-CPD- $Y$ was treated with phenacylbromide under the conditions which previously had been shown to modify a methionyl residue in CPD-Y (see section 2.2.2) causing drastic alterations of its activities (7). It was found that this treatment of Met-SO-CPD-Y had no influence on any of its activities and consequently, it may be inferred that phenacylbromide does not react with MetSO-CPD-Y because the methionyl residue it reacts with in unmodified $C P D-Y$ had been oxidized in Met-SO-CPD-Y.

Treatment of CPD-Y with $\mathrm{H}_{2} \mathrm{O}_{2}$ in $0.1 \mathrm{M}$-sodium acetate under conditions otherwise identical to those employed in Figure 1 altered the course of the reaction (Figure $3 \mathrm{~A}$ ). In the initial phases of the reaction the activities towards FA-Phe $\downarrow$ Leu-OH, FA-Phe $-\mathrm{OMe}$, FA-Phe $-\mathrm{NH}_{2}$ and FA-Phe - Gly- $\mathrm{NH}_{2}$ all decreased. However, after approximately one hour a second reaction appeared which caused all activities of CPD-Y to increase over the next seven hours. The modified enzyme obtained after 8 hours reactions contained two equivalents of Met-SO while it was otherwise identical to unmodified CPD-Y in terms of amino acid composition, UV-spectrum and sulfhydryl and carbohydrate content. Using affinity chromatography to separate modified from unmodified enzyme it was found that the preparation obtained after 8 hours reaction contained less than $1 \%$ residual CPD-Y and consequently, the activity changes observed in Figure $3 \mathrm{~A}$ can be correlated with the modification of two methionyl residues. Since the activities of CPD-Y within the first hour of reaction were affected in a manner similar to that observed with phosphate buffer as the reaction medium (Figure 1A) and since a simultaneous increase in the Met-SO content to approximately $\mathrm{I}$ equivalent is observed (Figure $3 \mathrm{~B}$ ) it is probable that the methionyl residue oxidized in phosphate buffer is also oxidized in this early phase of the reaction in acetate buffer. The 


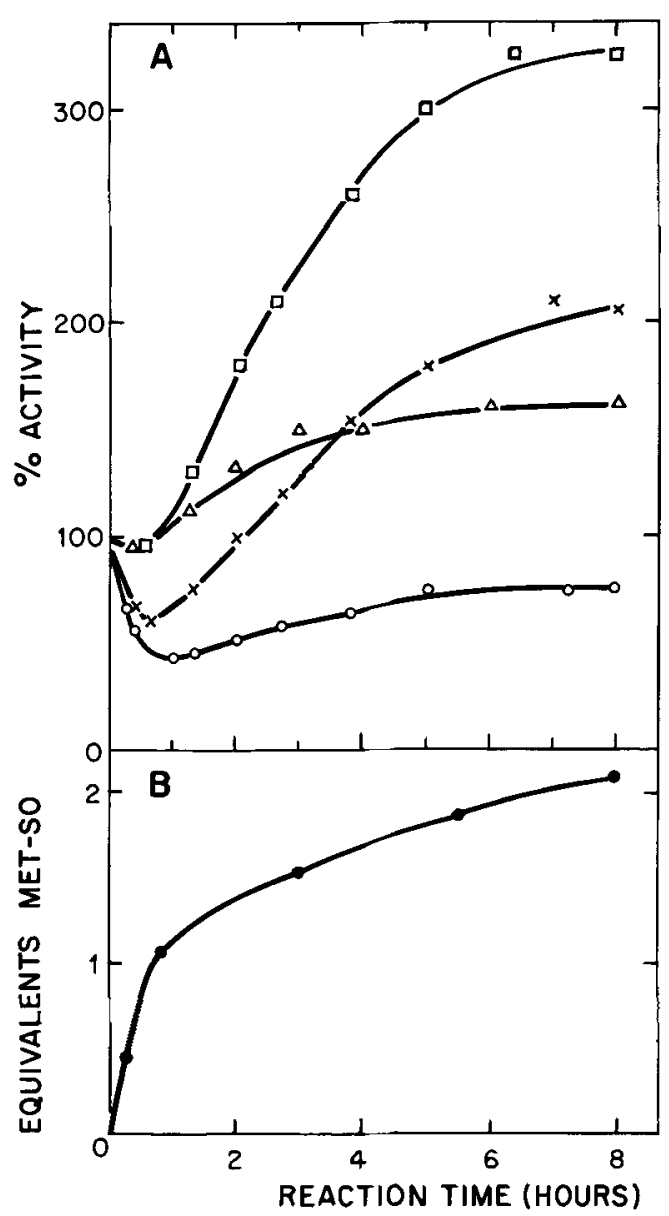

Figure 3. Modification of CPD-Y with $\mathrm{H}_{2} \mathrm{O}_{2}$. Reaction conditions: $5.3 \mathrm{mg} / \mathrm{ml} \mathrm{CPD}$. $Y, 0.1 \mathrm{M}$-sodium acetate, $0.19 \mathrm{M}-\mathrm{H}_{2} \mathrm{O}_{2}, \mathrm{pH} 4.75$. The activities of the enzyme were assayed during the reaction ( $($ anel $A)$ and the number of Met-SO residues determined (Panel B) as described in Figure 1.

following phase of the reaction (Figure 3B) then represents the slower oxidation of an additional methionyl residue.

The influence of the reaction medium, phosphate or acetate buffer, on the number of methionyl residues being oxidized with $\mathrm{H}_{2} \mathrm{O}_{2}$ can be explained either by acetate binding to the enzyme thereby exposing an additional methionyl residue or by the potent oxidizing reagent peracetic acid being formed from $\mathrm{H}_{2} \mathrm{O}_{2}$ and acetic acid. Of these two possibilities the latter is the more probable since a prior 3 hours incubation of buffer and $\mathrm{H}_{2} \mathrm{O}_{2}$ before enzyme is added

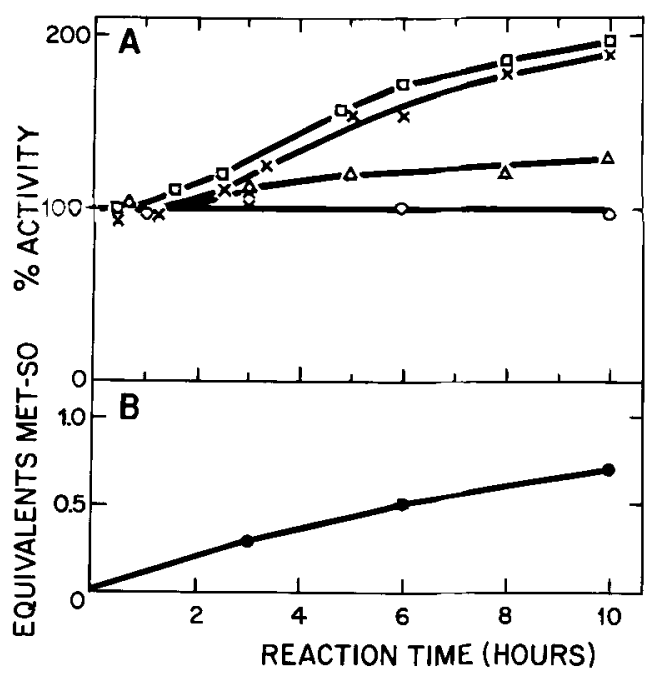

Figure 4. Modification of CPD-Y in the presence of benzylsuccinic acid. Reaction conditions: $5.3 \mathrm{mg} / \mathrm{ml}$ CPD-Y, $0.1 \mathrm{M}$-sodium acetate, $5 \mathrm{~mm}$-benzylsuccinic acid, $1.3 \%$ ethanol, $0.19 \mathrm{M}-\mathrm{H}_{2} \mathrm{O}_{2}, \mathrm{pH} 4.75$. The activities of the enzyme were assayed during the reaction (Panel A) and the number of Met-SO residues determined (Panel B) as described in Figure 1.

increased the rate of the reaction significantly.

(Met-SO) ${ }_{2}$-CPD-Y was found to inactivate at $50{ }^{\circ} \mathrm{C}$ in an apparent first order reaction with a rate constant $\mathrm{k}$ of $0.11 \mathrm{~min}^{-1}$ as compared with $4.9 \cdot 10^{-3} \mathrm{~min}^{-1}$ for the Met-SO-CPD-Y. The influence of the temperature on $\mathrm{k}$ indicated that this reaction had an activation energy $E_{\mathrm{a}}$ of 200 $\mathrm{kJ} \cdot \mathrm{mol}^{-1}$ as compared with $310 \mathrm{~kJ} \cdot \mathrm{mol}^{-1}$ for Met-SO-CPD-Y. Thus, the introduction of an oxygen atom on the second methionyl residue appears to have a pronounced destabilizing effect on the enzyme.

When the reaction with $\mathrm{H}_{2} \mathrm{O}_{2}$ in acetate buffer was performed in the presence of benzylsuccinic acid the activities of CPD-Y towards FA-Phe$\mathrm{NH}_{2}$, FA-Phe $\downarrow_{\text {Gly- }} \mathrm{NH}_{2}$ and FA-Phe-OMe increased while that towards FA-Phe-Leu-OH remained unchanged (Figure 4A). The modified enzyme deviated from the unmodified enzyme only by its content of Met-SO which increased from 0 to 0.7 equivalents after 10 hours reaction (Figure 4B). The absence of an initial phase where all activities of CPD-Y decrease due to oxidation of the first methionyl residue, as observed in the absence of benzylsuccinic acid 


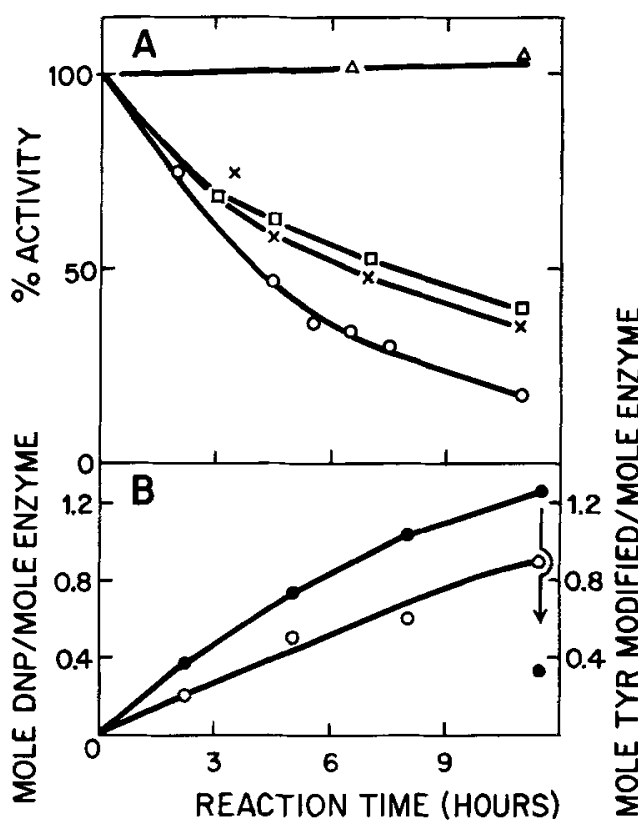

Figure 5. Modification of CPD-Y with FDNB. Reaction conditions: $3.9 \mathrm{mg} / \mathrm{ml} \mathrm{CPD-Y,} 0.08 \mathrm{M}-\mathrm{NaH}_{2} \mathrm{PO}_{4}$, $14 \mathrm{mM}-{ }^{14} \mathrm{C}-\mathrm{FDNB}, 2.5 \%$ ethanol, $\mathrm{pH}$ 6.0. The activities of the enzyme were measured as described in Figure 1 (Panel A). At various times aliquots of the reaction mixture were desalted and the radioactivity and the amino acid composition determined (Panel B). The radioactivity was expressed as mole $\mathrm{DNP} /$ mole enzyme (---). The amino acid composition indicated that only the content of tyrosine was affected and the results were expressed as number of tyrosyl residues modified per mole enzyme (-O-O-O-). Thiolysis of the modified enzyme (see Figure 6) caused a reduction in the ${ }^{14} \mathrm{C}$-DNP-content (indicated by an arrow).

(Figure 3A), indicates that this particular methionyl residue is not oxidized in the presence of benzylsuccinic acid. The activity changes seen in Figure 4A are more likely due to oxidation of the second methionyl residue. Thus, regardless of the reaction medium, phosphate (see above) or acetate buffer, benzylsuccinic acid protects the methionyl residue which otherwise is the one being most susceptible to oxidation. On the other hand, the rate of oxidation of the second methionyl residue is only reduced by approximately $50 \%$ by the presence of benzylsuccinic acid, suggesting that this methionyl residue is located in a different portion of the molecule than that to which benzylsuccinic acid binds.

\subsection{Modification with fluorodinitrobenzene (FDNB)}

Treatment of CPD-Y with FDNB for five hours at $\mathrm{pH} 8.0$ resulted in the modification of approximately five lysyl residues, two histidyl residues and six tyrosyl residues as determined by amino acid analysis of acid hydrolysates of the modified enzyme. The p-HMB titration indicated that the single cysteinyl residue of the enzyme was not affected by the reaction. By lowering the $\mathrm{pH}$ of the reaction medium to 6.0 it was achieved that the reaction was limited to a single tyrosyl residue while less than 0.2 lysyl and histidyl residues were modified. The course of the reaction was studied in detail using ${ }^{14} \mathrm{C}$-FDNB as the reagent and the activities of CPD-Y towards FA-Phe-Leu-OH, FA-Phe- $\mathrm{NH}_{2}$ and FA-Phe - Gly- $\mathrm{NH}_{2}$ decreased while that towards FA-Phe $-O M e$ remained constant or increased slightly (Figure 5A). Using affinity chromatography to separate modified from unmodifed enzyme (see section 2.2.3) it was established that the reaction mixture after 11 hours (Figure 5A) contained only 10\% residual CPD-Y and that the modified enzyme exhibited approximately $5 \%$ activity towards FA-Phe $\downarrow$ Leu-OH. Thus, the modification of $90 \%$ of the enzyme was correlated with the loss of 0.9 residues tyrosine and with the incorporation of 1.2 equivalents of reagent as determined from the radioactivity measurements (Figure $5 \mathrm{~B}$ ). These results indicate that it is modification of a single tyrosyl residue with FDNB to form a O-DNP-tyrosyl residue which alters the enzymatic properties of the enzyme.

Tyrosine and histidine can be regenerated from O-DNP-tyrosine and $\mathrm{N}^{\mathrm{Im}}$-DNP-histidine by treatment with thiol compounds without affecting $\mathrm{N}^{\mathrm{e}}$-DNP-lysine and $\mathrm{N}^{\mathrm{a}}$-DNP-amino acids (19). Thus, provided a tyrosyl residue is the site of reaction with ${ }^{14} \mathrm{C}$-FDNB, treatment with mercaptoethanol should release the radioactive label attached to the enzyme. The preparation of CPD-Y obtained after 11 hours reaction with FDNB (see Figure 5A) was treated with $0.14 \mathrm{M}$-mercaptoethanol at $\mathrm{pH} 8.0$ and the 
reaction was followed by recording the spectrum between 300 and $400 \mathrm{~nm}$ (Figure 6). Using the molar extinction of 12500 for S-DNP-mercaptoethanol in dimethylformamide (19) the increase in absorption at $341 \mathrm{~nm}$ (see insert) corresponds to a loss of 0.65 equivalent DNP from the modified enzyme. However, the radioactivity content of the enzyme after thiolysis for $2 \mathrm{~h} 20 \mathrm{~min}$ and dialysis corresponded to 0.3 equivalent, i.e. a loss of 0.9 equivalent. This indicates that 0.3 equivalent DNP is attached to lysine while the residual 0.9 equivalent is attached to tyrosine or histidine, and this is consistent with the results of the amino acid analysis which indicates that 0.9 tyrosyl residue and less than 0.2 equivalent histidine was modified by FDNB.

When the reaction was performed in the presence of the competitive inhibitor Z-D-Ala-LPhe-OH (1) the activity of CPD-Y towards FA-Phe-Leu-OH was reduced by only $10 \%$ within 6 hours of reaction with FDNB. Thus, Z-D-Ala-L-Phe-OH protects the enzyme towards reaction with FDNB, suggesting that the tyrosyl residue modified by this reagent in the absence of Z-D-Ala-L-Phe-OH is located in the active site of the enzyme.

DNP-CPD-Y was characterized kinetically using the series of FA-substrates employed in the characterization of Met-SO-CPD-Y. It is apparent from the results in Table II that DNPCPD-Y hydrolyzed all ester and peptide substrates with reduced $k_{c a t}$ values relative to unmodified CPD-Y and, apart from FA-Phe-OMe, with increased $K_{m}$ values. $K_{c a t} / K_{m}$ was influenced by the modification in a manner which depends on the size of the leaving group: for the ester substrate FA-Phe-OMe, characterized by a nonbulky leaving group, $\mathbf{k}_{\mathrm{cal}} / \mathrm{K}_{\mathrm{m}}$ remained unchanged while it was reduced for the ester substrates with more bulky leaving groups, i.e. FA-Phe $\_$OEt, FA-Ala $\downarrow$ OEt and FA-Ala-OBzl. DNP-CPD-Y hydrolyzed all peptide and amide substrates with reduced $k_{\text {ral }} / K_{m}$ values relative to CPD-Y but the magnitude of the reduction depended on the size of the leaving group. Thus, $k_{\text {cat }} / K_{m}$ for the hydrolysis of FA-Phe-Gly-OH by DNP-CPD-Y is $10 \%$ of the value obtained with unmodified CPD-Y while for FA-Phe-Leu-OH it was only $1 \%$ of the value obtained with CPD-Y

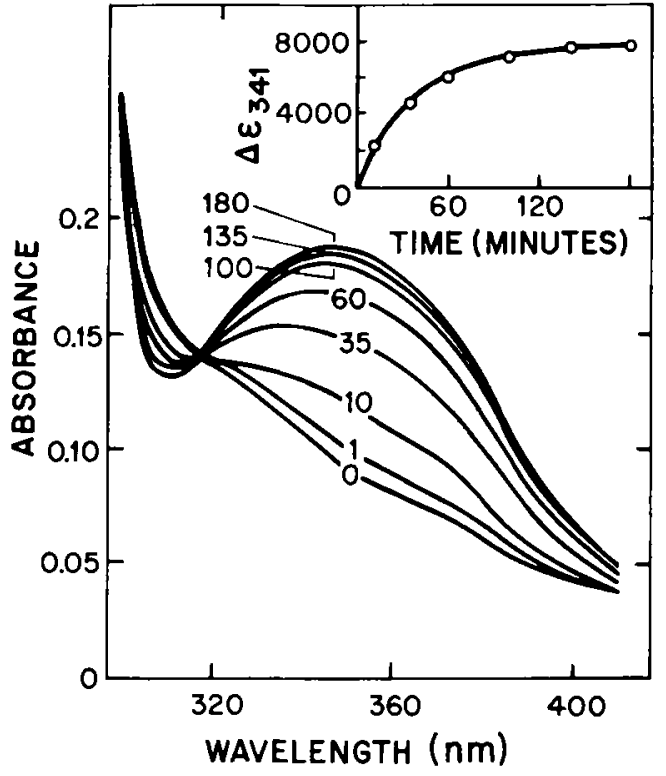

Figure 6. Thiolysis of DNP-CPD-Y obtained after $11 \frac{1}{2}$ hours reaction (see Figure 5). Reaction conditions: $0.68 \mathrm{mg} / \mathrm{ml}$ CPD-Y, $0.05 \mathrm{M}-\mathrm{NaH}_{2} \mathrm{PO}_{4}, 0.14 \mathrm{M}$-mercaptoethanol, pH 8.0. The spectrum between 300 and $450 \mathrm{~nm}$ was recorded as a function of time and in the insert $\Delta \varepsilon_{3+1}$ is plotted versus time.

(Table II). Similarly, $k_{c a t} / K_{m}$ for the hydrolysis of FA-Phe $-\mathrm{NH}_{2}$ was approximately $50 \%$ of the value obtained with CPD-Y while for FA-PheVal- $\mathrm{NH}_{2}$ it was only $1 \%$ of the value obtained with unmodified CPD-Y (Table II). Thus, introduction of the DNP group into the active site of the enzyme affects the specificity of the enzyme with respect to the leaving group of all types of substrate such that substrates with non-bulky leaving groups relatively become better substrates of the enzyme than those with bulky leaving groups, suggesting that the DNP group prevents a favorable interaction with the latter type of substrates. These results indicate that the tyrosyl residue being modified by FDNB is located in the $S$, binding site of the enzyme.

\section{DISCLSSION}

Alkylation of a methionyl residue located in the $S_{i}$ binding site has previously been shown to cause drastic alterations in the leaving group specificity of the enzyme (7). In the present 
paper oxidation of the same methionyl residue with $\mathrm{H}_{2} \mathrm{O}_{2}$ and modification of a tyrosyl residue similarly located in the $S_{1}$ binding site have also been found to cause alterations in the leaving group specificity and consequently, it is relevant to compare the effects of all these modifications on the enzymatic properties of CPD-Y.

CPD-Y catalyzed hydrolysis of peptide, amide and ester substrates is assumed to proceed via an acyl-enzyme intermediate in reactions where the acylation step is rate-limiting (3). In case this is generally true, $k_{\text {cat }}$ is a measure for the rate of acylation $\left(k_{2}\right)$ and $K_{m}$ for $K_{s}$, the dissociation constant of the enzyme-substrate complex. Since Met-SO-CPD-Y hydrolyses ester substrates with increased $k_{\text {cat }}$ it is suggested that the introduction of a sulfoxide group into the $S_{i}^{\prime}$ binding site increases the rate of acylation of ester substrates. p-NPAB-CPD-Y similarly hydrolyses ester substrates with increased $k_{\text {cat }}$ while IAA-CPD-Y, PAB-CPD-Y, m-NPABCPD-Y and DNP-CPD-Y all hydrolyse ester substrates with decreased $\mathrm{k}_{\text {car }}$. The present results and those previously published (7) do not allow the causes of these effects to be established but it is probable that the introduction of the sulfoxide group changes the polarity of a portion of the $S_{1}^{\prime}$ binding site and a similar effect may be attributed to the p-nitrophenacylsulfonium group containing the polar nitro group.

All the alkylated derivatives of CPD-Y, i.e. IAA-CPD-Y, PAB-CPD-Y, p-NPAB-CPD-Y and $\mathrm{m}-\mathrm{NPAB}-\mathrm{CPD}-\mathrm{Y}$ hydrolyse peptides with $\mathrm{k}_{\text {cat }}$ values that are only $0.5-4 \%$ of the values obtained with unmodified CPD-Y. This drastic reduction is probably not due to the loss of the methionyl residue since Met-SO-CPD-Y with the same methionyl residue oxidized hydrolyses peptides with much higher $\mathrm{k}_{\text {cat }}$ values, i.e. 35$50 \%$ of the values obtained with CPD-Y. Instead, it appears that the low $\mathbf{k}_{\text {cat }}$ values of the alkylated derivatives are due to the nature of the group introduced into these enzymes. The bulkiness of this group is not likely to be the cause since IAA-CPD-Y and PAB-CPD-Y contain groups of different bulkiness and yet hydrolyse peptides with essentially the same $k_{\text {cal }}$ values. It is conceivable that the positively charged sulfonium ion common to all these alkylated derivatives is responsible. Such a group is not found in Met-SO-CPD-Y and consequently, this enzyme hydrolyses peptides with much higher $\mathrm{k}_{\mathrm{cat}}$ values. It appears that introduction of the DNP group in the $S_{i}$ binding site reduces $k_{\text {cat }}$ for peptide hydrolysis somewhat more than observed for Met-SO-CPD-Y but not nearly as much as observed for the alkylated derivatives.

In general, all the described modifications increase $K_{m}$ for both ester and peptide hydrolysis indicating that these groups have an adverse effect on the binding of such substrates. However, two exceptions should be mentioned: DNP-CPD-Y and PAB-CPD-Y both hydrolyse FA-Phe-OMe with decreased $K_{m}$ values suggesting that the introduction of these two groups into the enzyme has a beneficial effect on the binding of this substrate. This suggests that in these two cases the combination of a substrate with a non-bulky leaving group, characterized by a relatively high $\mathrm{K}_{\mathrm{m}}$, and a bulky hydrophobic group occupying a position in the $S_{1}^{\prime}$ binding site, mimics a substrate with a bulky leaving group which is characterized by a low $\mathrm{K}_{\mathrm{m}}$.

Due to the drastically altered leaving group specificity some of the alkylated derivatives catalyzes deamidation reactions in much higher yields than unmodified CPD-Y (7) and these enzymes presumably will have applications in enzymatic peptide synthesis. The alkylated CPD-Y derivatives are examples of how a proteolytic enzyme can be adapted to specific purposes by protein engeneering and it is probable that other modified enzymes, exopeptidases as well as endopeptidases, similarly with advantage could be applied in many reactions in place of existing unmodified enzymes. Conceivably such derivatives could be obtained not only by chemical modifications but also by site directed mutagenesis. DNP-CPD-Y and Met-SO-CPD$Y$ described in the present paper also exhibits an altered leaving group specificity but the alterations are not sufficient for these enzymes to be of use in deamidation reactions. However, an altered leaving group specificity implicates an altered specificity towards nucleophiles in aminolysis reactions, and DNP-CPD-Y and Met-SO-CPD-Y might conceivably have applications in this type of reactions.

Of the five methionyl residues in CPD-Y one appears to be freely accessible since it easily 
reacts with $\mathrm{H}_{2} \mathrm{O}_{2}$ while a second is only partially accessible since it reacts rather slowly with $\mathrm{H}_{2} \mathrm{O}_{2}$. The remaining three methionyl residues are probably buried in the interior of the molecule since they do not react at all. The stability of the enzyme is not affected when the accessible methionyl residue is modified, but when the partially exposed methionyl residue is modified the stability is drastically reduced. This is remarkable since only a non-bulky oxygen atom is introduced on its side-chain, and it suggests that the protein molecule is densely packed around this second methionyl residue.

Chymotrypsin $(11,12,13,16)$ and subtilisin (20) have each been shown to contain a methionyl residue which is easily oxidized by $\mathrm{H}_{2} \mathrm{O}_{2}$. Both are located in the active site but not in the $S_{\uparrow}^{\prime}$ binding site. Chymotrypsin in addition contains a methionyl residue which reacts with $\mathrm{H}_{2} \mathrm{O}_{2}$ in 7 M-urea. However, the influence of this modification on the stability of the enzyme has not been studied such that the effects of a buried Met-SO group on the stability of the enzyme cannot be evaluated in this case.

\section{ACKNOWLEDGEMENTS}

I am indepted to Professor MARTIN OTTESEN for invaluable advise during the work and for critically revising the manuscript. Ms. IRENE SIMONSEN is gratefully acknowledged for excellent technical assistance.

\section{REFERENCES}

1. BaI, Y., R. Hayashi \& T. Hata: Kinetic studies of carboxypeptidase Y. II. Effects of substrate and products analogs on peptidase and esterase activities. J. Biochem. 77, 81-88 (1975)

2. BaI, Y. \& R. Hayashi: Properties of the single sulfhydryl group of carboxypeptidase $Y$. Effects of alkyl and aromatic mercurials on activities towards various synthetic substrates. J. Biol. Chem. 254, 8473-8479 (1979)

3. BREDDAM, K.: Modification of the single sulfhydryl group of carboxypeptidase $Y$ with mercurials. Influence on enzyme specificity. Carlsberg Res. Commun. 48, 9-19 (1983)

4. BREdDAm, K., S. SøRENSEN \& M. OtTeSEn: Isola- tion of a carboxypeptidase from malted barley by affinity chromatography. Carlsberg Res. Commun. 48, 217-230 (1983)

5. BREDDAM, K., F. WidMer \& J.T. Johansen: Amino acid methyl esters as amine components in CPD-Y catalyzed peptide synthesis. Control of side-reactions. Carlsberg Res. Commun. 48, 231237 (1983)

6. BREDDAM, K. \& J.T. JohansEn: Semisynthesis of human insulin utilizing chemically modified carboxypeptidase Y. Carlsberg Res. Commun. 49, 463-472 (1984)

7. BREDDAM,K.: Chemically modified carboxypeptidase $Y$ with increased amidase activity. Carlsberg Res. Commun. 49, 535-554 (1984)

8. Dubois, M., K.A. Gilles, J.K. Hamilton, P.A. REBERS \& F. SMITH: Colorimetric method for determination of sugar and related substances. Anal. Chem. 38, 350-356 (1956)

9. HaYashi, R., J. Bai \& T. HaTA: Kinetic studies of carboxypeptidase $Y$. I. Kinetic parameters for the hydrolysis of synthetic substrates. J. Biochem. 77, 69-79 (1975)

10. Johansen, J.T., K. BReddam \& M. OTtesen: Isolation of carboxypeptidase $Y$ by affinity chromatography. Carlsberg Res. Commun. 41, 1-14 (1976)

11. KNOWLES, J.R.: The role of methionine in chymotrypsin-catalyzed reactions. Biochemical J. 95, 180-190 (1965)

12. Koshland, D.E. \& D.N. STRumeyer \& W.J. Ray: Amino acids involved in the action of chymotrypsin. Brookhaven Symp. Biol. 15, 101 (1962)

13. Mor, G., A. Ehret \& S.G.COHEN: Stereoselectivity and reactivity of chymotrypsin modified at methionine-192. Arch. Biochem. Biophys. 174, 158166 (1976)

14. RIORDAN, J.F. \& B.L. VALLEE: Reactions with Nethylmaleimide and p-mercuribenzoate. Methods Enzymol 11, 541-548 (1967), Eds. C.H.W. Hirs, Academic Press

15. SAVIGE, W.E. \& A. Fontana: Interconversion of methionine and methionine sulfoxide. Meth. Enzymol. 47, 453-459 (1977), Eds. C.H.W. Hirs \& S. Timasheff, Academic Press

16. SChachter, H., K.A. Halliday \& G.H. Dixon: An alteration in the reactivity of chymotrypsin and trypsin towards hydrogen peroxide in the presence of specific substrates. J. Biol. Chem. 238, 3134-3136 (1964)

17. SChechter, I. \& A. Berger: On the size of the active site of proteases. I. Papain. Biochem. Biophys. Res. Commun. 27, 157-167 (1967)

18. SEGEL, I.: Biochemical calculations. John Wiley \& Sons, New York, pp. 393-395 (1968) 
K. BREDDAM: Binding sites of carboxypeptidase $Y$

19. Shaltiel, S.: Dinitrophenylation and thiolysis as a tool in protein chemistry. Israel J. Chem. 12, 403-419 (1974)

20. Stauffer, C. E. \& D. Etson: The effect on subtilisin activity of oxidizing a methionine residue.

J. Biol. Chem. 244, 5333-5338 (1969)

Accepted by: H. KLenow, E. Lund and S. O. ANDERSEN 